\title{
Quantifying benefits of energy efficient house design through monitoring of specified air quality and household energy activity
}

\author{
M Wentzel \\ Palmer Development Consulting
}

\begin{abstract}
Energy efficient building design aims to use passive design principles such as orientation, insulation, materials and surrounding area layout to minimise the need for active space heating or cooling. Implementation of the principles of energy efficient design in specifically low-cost houses delivered by government can have numerous benefits such as monetary savings, increased comfort and health indoor environments for homeowners and inhabitants. The project described here measured the indoor air quality of six energy efficient houses in two project areas as well as energy activity and potential benefits related to energy efficient house design. It was concluded that a small reduction in $\mathrm{CO}_{2}$ is achieved in an energy efficient house when compared with a conventional house. However, the reduction achieved is dependent on the type of fuel used for space heating. Overall, the energy efficient houses observed in the project were more comfortable and households spent less on space heating requirements than conventional houses. It is recommended that the principles of energy efficient design should be a minimum requirement in low-cost housing delivery.
\end{abstract}

Keywords: energy efficient design, low-cost housing, air quality, Benoni, Lady Grey, space heating, fuel expenditure

\section{Introduction}

A house or a building can be thought of as being an envelope, which shelters an indoor space from the weather outside (Holm, 1997). The objective of the envelope is to maintain a comfortable inside environment regardless of how hot or cold or windy it gets outside. One way to achieve this is to construct the building and then force the inside temperature to be comfortable, but a better way is to design the building with more consideration for its environment so that the need for active space heating or cooling by mechanical or electrical means is substantially reduced, if not totally eliminated. Through the use of solar passive design principles, the minimum or no active space heating is required in houses under normal climatic conditions, therefore it is also referred to as 'zero energy' houses. Solar passive design principles include design and orientation of the house, as well as the building material used (that is mass, glazing, insulation, use of daylight, ventilation and other systems which might be required).

In South Africa, attempts have been made to convince government to include energy efficient design principles in the delivery of low cost housing, since this would have numerous benefits to the lowincome families living in these houses (Adelaja et al., 1990). Ordinary low-cost houses may be cheap to build, but their running costs are high. Because of the use of energy-inefficient materials, it is sometimes warmer outside the house than inside. The costs of keeping these houses at comfortable indoor temperatures come out of the earnings of people who can least afford to pay them - heating can cost poor people up to $66 \%$ of their income (Palmer Development Consulting, 2003). It is however, not only in South Africa or the development context that energy efficient building design is applicable. In Europe, the European Union is implementing minimum energy efficiency standards to ensure buildings are climatically conscious and sustainably designed (Swedish Standards Institute, 2004).

Furthermore, poor families use dirty, dangerous fuels such as coal and paraffin to heat their homes. These fuels cause indoor and outdoor air pollution leading to respiratory diseases and are dangerous in terms of causing fires and burns (Terblanche, et al, 1992). For example, it has been calculated that air 
pollution resulting from domestic fuel burning and the resultant respiratory illnesses is costing Government approximately R1.1 billion per annum (Trade and Industry Chamber, 2004). In January 2004, the Department of Housing (Sekhonyana, 2004) announced that the energy efficient housing concept would become part of the South African government's policy for low cost housing delivery.

Energy efficient housing design may benefit homeowners in numerous ways, for example, fuel savings, monetary savings and improved indoor comfort and air quality (Holm and Viljoen, 1996). On the collective benefits, the aggregate reduction in energy demand for space heating would facilitate environmental conservation, reduce peak electricity demand and postpone the need for additional electricity generation capacity. The research results presented below illustrate that inhabitants of lowincome energy efficient houses experience benefits.

\section{Methodology}

The objective of the study was to ascertain the advantages of energy efficient demonstration houses with regard to their energy-efficiency and socioeconomic aspects. Monitoring was carried out in two of four project areas where the Dutch Ministry of Foreign Affairs financed the design and construction of 16 low-cost energy-efficient houses. Monitoring activities included air quality (measuring methane $\left(\mathrm{CH}_{4}\right)$, oxygen $\left(\mathrm{O}_{2}\right)$, carbon dioxide $\left(\mathrm{CO}_{2}\right)$, carbon monoxide $(\mathrm{CO})$ and hydrogen sulphide $\left(\mathrm{H}_{2} \mathrm{~S}\right)$ at ten-minute intervals) as well as intensive monitoring of household energy activities and inhabitant behaviour on a daily basis. Energy efficient houses as well as control houses selected to match the profile (socio-economic and energy consumption and expenditure) of energy efficient households were monitored.

Prior to air quality monitoring, a baseline study was carried out in the project areas which interviewed households, energy suppliers, clinics; health centres and local authorities. The aim of the baseline study was to select control houses, determine general energy use patterns, gain an overview of the perception, level of knowledge and acceptance of energy efficient housing and to determine the incidence of respiratory disease, fires and burns per area.

In total, six energy efficient houses and eight control group houses were monitored during the course of the project. Air quality monitoring was done with a portable data logger measuring $\mathrm{CH} 4$, $\mathrm{O}_{2}, \mathrm{CO}_{2}, \mathrm{CO}$ and $\mathrm{H}_{2} \mathrm{~S}$ ) at ten-minute intervals. The alarm settings of the data logger were switched to maximum, in order to continue with measurements even if alarm conditions occurred. The high and low alarm settings for all the sensors were set at the same level. For methane it was at $90 \% \mathrm{LEL}, \mathrm{O}_{2}$ was at 10.00 vol. \%, $\mathrm{CO}$ was at $200 \mathrm{ppm}, \mathrm{CO}_{2}$ was at
3.00 vol. \% and $\mathrm{H}_{2} \mathrm{~S}$ was at $50 \mathrm{ppm}$. Air quality monitoring continued for a period of seven days during the winter of 2004.

Energy activity and user behaviour was monitored through a set of four questionnaires and included daily household visits throughout the monitoring period. Data collection through the questionnaire system commenced in May 2004 and continued through the winter until August 2004.

\section{Air quality monitoring results: Benoni and Lady Grey}

Although the levels of gases measured were within the World Health Organisation's acceptable range, the air quality in the control house in Benoni was found to be slightly better than the air quality in the energy efficient house in Benoni. The main reason for this is the fact that the control house used an electric heater while the energy efficient house made use of a paraffin space heater. Change in gaseous levels in the energy efficient house corresponds to the start of space heating activities in the colder evenings during winter. As an example, carbon monoxide levels in the energy efficient house and the control house is illustrated below.

Carbon monoxide levels are considered normal between 1-99ppm. Carbon monoxide levels ranged between $4 \mathrm{ppm}$ and $-4 \mathrm{ppm}$ in the control house. In the energy efficient house, a clear spike can be observed from 18:46 onwards. The spike corresponds with the start of space heating by means of a paraffin space heater.

Although levels of gases measured in both the energy efficient and control houses were within the range which is accepted as normal, the energy efficient houses in Lady Grey performed slightly better than the control houses with slightly lower levels of gasses measured. The biggest difference was found in the carbon monoxide levels illustrated below.

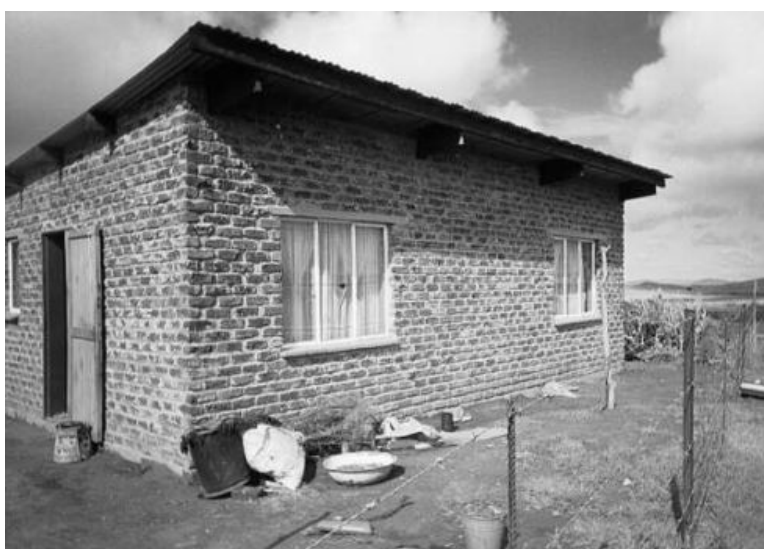

Figure 1: One of the energy efficient houses in Lady Grey

Note the longer roof overhang on the northern side providing shade in summer and allowing sunshine in during winter. Photograph: Marlett Wenzel 


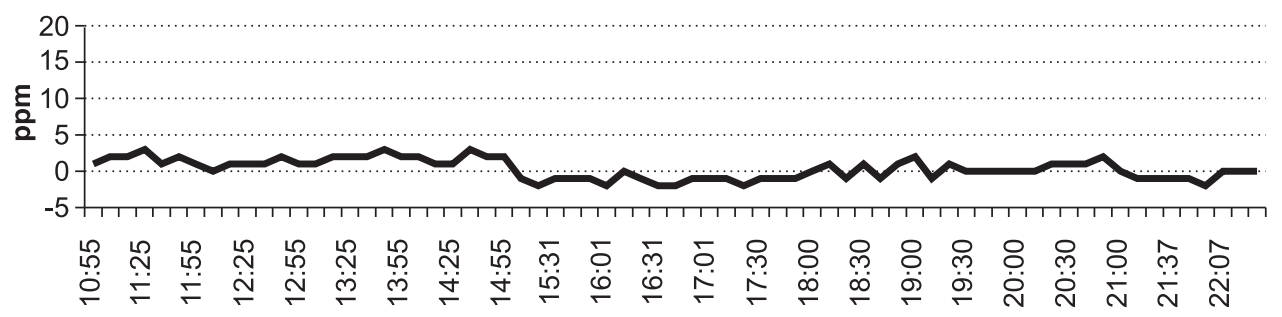

Figure 2: Carbon monoxide levels in the control house in Benoni

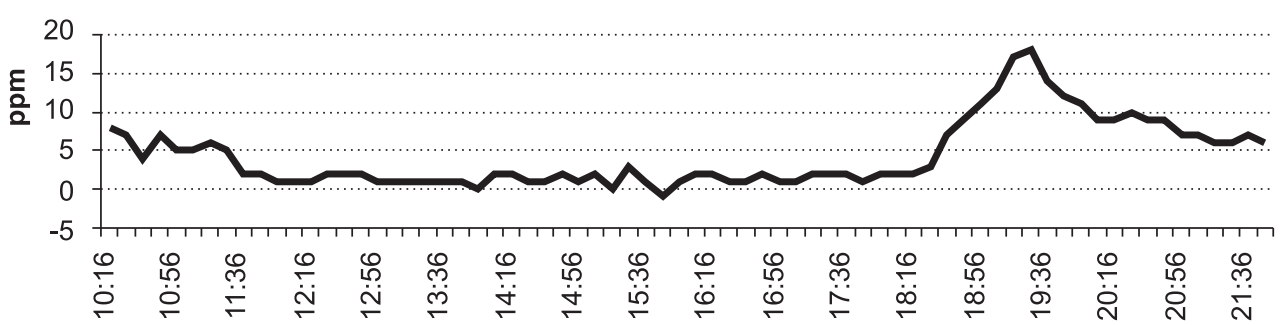

Figure 3: Carbon monoxide levels in the energy efficient house in Benoni

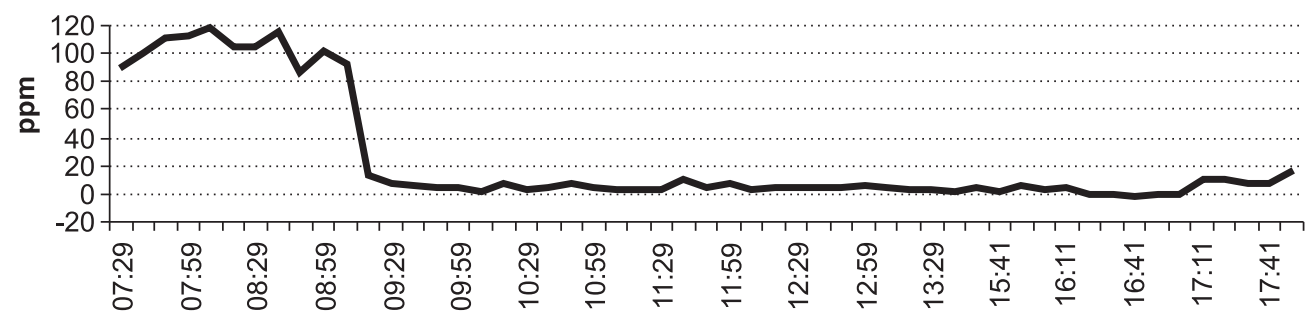

Figure 4: Carbon monoxide levels in the control house in Lady Grey

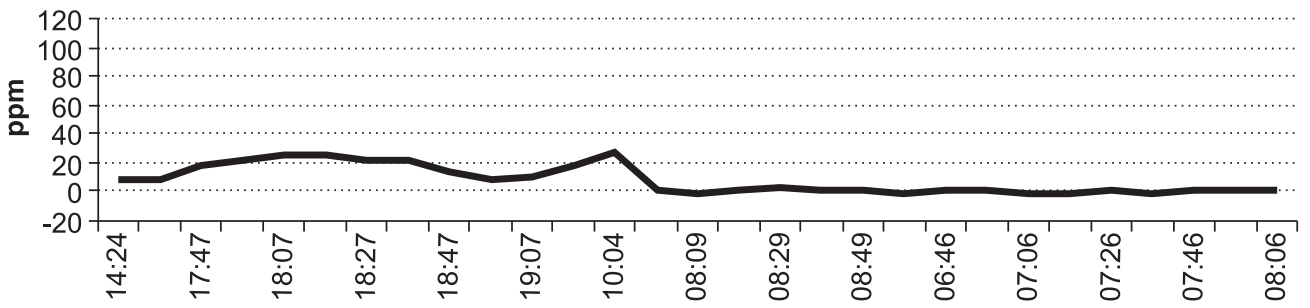

Figure 5: Carbon monoxide levels in the energy efficient house in Lady Grey

Carbon monoxide levels are considered normal between 1-99ppm and carbon monoxide levels in the control house were below the normal range. However, when the upper limits measured are compared to the energy efficient house, it can be seen that much higher levels of carbon monoxide were measured in the control house than in the energy efficient house. The highest level reached in the energy efficient house was $21 \mathrm{ppm}$, while the highest level in the control house was $120 \mathrm{ppm}$. The control house used mainly paraffin and coal for space heating purposes.

\section{Energy and behaviour monitoring Space heating requirements}

The control houses in Benoni used heaters for space heating for between six to nine hours per day, while the energy efficient houses used a heater for about five hours a day. Heaters were used on $70 \%$ of all monitored days in the control houses and on $65 \%$ of all monitored days (concurrently monitored) in the energy efficient houses. From this data, it was concluded that the energy efficient houses require less numbers of hours space heating per day; and the number of days that space heating is required is also less. Furthermore, a lower percentage of people in energy efficient houses (76\%) wore both a jersey and a jacket than in any control house (91\%). Wearing both a jersey and a jacket would indicate colder indoor temperatures, therefore, if less people wore a jacket and a jersey in the energy efficient house than in the control houses, it could be concluded that it is actually warmer in the energy efficient house. 
In Lady Grey, the energy efficient houses used a heater for fewer hours per day and heated their homes significantly less than the control houses, as indicated by the fact that the energy efficient houses only heated for $5 \%$ of the monitoring period compared to $66 \%$ and $22 \%$ of the control houses. One energy efficient house did not require space heating while the other energy efficient houses only heated their homes in the evening from 17:00 for an average of 4 hours per day. The control houses required space heating in the morning from 08:00 until 10:00 as well as in the evening, heating on average 5 hours per day.

A lower number of people in the energy efficient houses wore jerseys and jackets in the evening (38$74 \%$ ) than in the control houses (53-96\%), indicating higher thermal comfort in the energy efficient houses, and all residents in energy efficient houses experienced their homes as comfortable to hot.

\section{Fuel expenditure}

In terms of fuel expenditure, on average, energy efficient houses spent R382.50 per month on fuel, while the control houses spent R274 per month on fuel expenses in Benoni. The energy expenditure in Benoni is illustrated below.

Table 1: Cost of fuels per month - Benoni

\begin{tabular}{cccc}
\hline $\begin{array}{c}\text { Type of } \\
\text { house }\end{array}$ & Fuel & $\begin{array}{c}\text { Avg. cost } \\
\text { fuel/month }\end{array}$ & $\begin{array}{c}\text { Total cost of } \\
\text { fuel/month }\end{array}$ \\
\hline EEH & Electricity & $\mathrm{R} 243$ & $\mathrm{R} 463$ \\
& LPG & $\mathrm{R} 220$ & \\
\hline EEH & Electricity & $\mathrm{R} 227$ & $\mathrm{R} 302$ \\
& $\mathrm{IP}$ & $\mathrm{R} 75$ & \\
\hline Control H & Electricity & $\mathrm{R} 203$ & $\mathrm{R} 203$ \\
\hline Control H & Electricity & $\mathrm{R} 297$ & $\mathrm{R} 412$ \\
& Wood & $\mathrm{R} 10$ & \\
& Coal & $\mathrm{R} 105$ & \\
\hline Control H & Electricity & $\mathrm{R} 207$ & $\mathrm{R} 207$ \\
\hline
\end{tabular}

Thermal energy end-use activities (cooking, food warming, water heating, space heating, ironing and preparing tea) in the two energy efficient homes constituted $63 \%$ and $69 \%$ respectively of the energy end-use incidences conducted over the monitoring period, while thermal energy end-use activities in the three control houses constituted $56 \%, 57 \%$ and $59 \%$ respectively of the energy enduse incidences conducted over the monitoring period. Attempting to explain the reason why the energy efficient houses in Benoni spent more of their energy activities on thermal energy end-uses in comparison with the control houses, it should be noted that firstly, the households living in energy efficient houses are wealthier than the households in the control houses and therefore, just have more disposable income to spend on energy expenses.
Secondly, when only investigating space heating (the thermal energy end-use most likely to be influenced by energy efficient building design) energy efficient houses spent $13 \%$ and $8 \%$ respectively of their energy end-use activities on space heating in comparison with $11 \%, 13 \%$ and $10 \%$ of the control houses. The lowest percentage spent on space heating was therefore in an energy efficient house.

The energy expenditure in Lady Grey is illustrat-

\begin{tabular}{|c|c|c|c|c|}
\hline $\begin{array}{l}\text { Type of } \\
\text { house }\end{array}$ & $\begin{array}{c}\text { House } \\
n r\end{array}$ & $\begin{array}{l}\text { Fuel } \\
\text { type }\end{array}$ & $\begin{array}{l}\text { Av. cost } \\
\text { /month }\end{array}$ & $\begin{array}{l}\text { Total cost } \\
\text { /month }\end{array}$ \\
\hline $\mathrm{EEH}$ & 51257 & $\begin{array}{c}\text { Electricity } \\
\text { Paraffin } \\
\text { Wood }\end{array}$ & $\begin{array}{l}\text { R30 } \\
\text { R93 } \\
\text { Free }\end{array}$ & R123 \\
\hline $\mathrm{EEH}$ & 51258 & $\begin{array}{l}\text { Electricity } \\
\text { Paraffin }\end{array}$ & $\begin{array}{l}\text { R57 } \\
\text { R64 }\end{array}$ & R121 \\
\hline $\mathrm{EEH}$ & 51259 & $\begin{array}{c}\text { Electricity } \\
\text { Paraffin }\end{array}$ & $\begin{array}{l}\mathrm{R} 50 \\
\mathrm{R} 59\end{array}$ & R109 \\
\hline $\mathrm{EEH}$ & 51260 & $\begin{array}{l}\text { Electricity } \\
\text { Paraffin }\end{array}$ & $\begin{array}{l}\text { R38 } \\
\text { R60 }\end{array}$ & R98 \\
\hline Control H & 17 & $\begin{array}{l}\text { Electricity } \\
\text { Paraffin }\end{array}$ & $\begin{array}{l}\text { R77 } \\
\text { R63 }\end{array}$ & R140 \\
\hline Control H & 33 & $\begin{array}{l}\text { Electricity } \\
\text { Paraffin }\end{array}$ & $\begin{array}{l}\text { R105 } \\
\text { R121 }\end{array}$ & R126 \\
\hline Control $\mathrm{H}$ & 45 & Electricity & R113 & $\mathrm{R} 113$ \\
\hline Control H & 5928 & Electricity & R100 & R340 \\
\hline & & Gas & R240 & \\
\hline Control H & 51219 & $\begin{array}{c}\text { Electricity } \\
\text { Paraffin } \\
\text { Wood } \\
\text { Coal }\end{array}$ & $\begin{array}{c}\text { R80 } \\
\text { R106 } \\
\text { Free } \\
\text { R99 }\end{array}$ & R285 \\
\hline
\end{tabular}

ed below.

From Table 2, it can be seen that households in the energy efficient houses consistently spent less on energy expenses than households in the control houses. On average, thermal energy end-use activities constituted $66 \%$ of energy activities. Moreover, energy efficient houses in Lady Grey spent less than $1 \%$ of their thermal energy activities on space heating.

In general, households in the energy efficient houses were asked a number of questions to compare their current houses with their previous house. These questions related to indoor air quality, indoor thermal comfort and health. The Lady Grey households reported positively on all these aspects implying that they view their energy efficient houses as better than their previous houses. The Benoni houses were only positive about the indoor thermal comfort in summer which has improved and one house, which reported that the indoor air was cleaner, is probably so because this house previously used coal for space heating and they no longer 
use coal.

\section{Conclusions}

In terms of the reductions in household greenhouse gas (GHG) emissions, it can be concluded that a small reduction in $\mathrm{CO}_{2}$ is achieved in an energy efficient house. However, the reduction achieved is dependent on the type of fuel used for space heating - if the EEH is using a more polluting fuel (for example, paraffin) than the control house (using for example, electricity), $\mathrm{CO}_{2}$ savings may not be detectable.

Secondly, regarding improvement in local and indoor air quality and thus a reduction in the incidence of respiratory disease, households in Lady Grey responded positively to questions regarding a reduction in the frequency of illness and children coughing in winter. This would indicate that the perception exists that an EEH may be healthier than a normal house.

With regard to the improvement in overall quality and comfort of the dwelling, inhabitants of the energy efficient house in Lady Grey found the dwelling more comfortable in both winter and summer, while Benoni EEH only found the house cooler in summer. In conclusion, the study found that households reported a positive improvement in the overall comfort of the dwelling. lows:

General conclusions can be summarised as fol-

- Energy efficient houses do save energy and reduce the energy consumption of inhabitants;

- Energy efficient houses specifically save on energy required for space heating;

- Evidence was found to conclude that energy savings also resulted in time savings, especially for women; and

- Reported health improvements indicate positive health benefits associated with energy efficient housing design.

\section{Recommendations}

- Energy efficient housing design should be promoted as a minimum standard for low-cost housing, since benefits include improved thermal comfort levels, monetary savings, time savings and health benefits to households;

- Due to the low level of $\mathrm{CO}_{2}$ savings realised on an individual house level, $\mathrm{CO}_{2}$ savings would need to be considered on a project or even multi-project level to become interesting for potential clean development mechanism (CDM) funding;

- To maximise benefits associated with energy efficient design, houses should operate at an optimum level. The lack of maintenance may reduce the performance and resulting benefits of the house. Maintenance issues should be addressed through the proposed training pro- gramme;

- Should energy efficient low-cost houses be supplied under housing delivery schemes, inhabitants of energy efficient houses should be thoroughly trained and informed on how to maximise the performance and benefits of an energy efficient house;

- Health impacts can actually only be monitored through longitudinal studies, linked to monitoring of clinics, health centres and hospitals. Should verification of health impacts be required, a suitable, longitudinal study should be carried out, in co-operation with health authorities; and

- To gather more as well as more reliable data, a bigger sample for monitoring would be beneficial. This would however, depend on the available energy efficient houses to monitor.

\section{References}

Adelaja, A.A; D.K. Irurah, D.K; Annegarn, H.J and Guy, D.L. 1990. Opportunities and constraints to energy efficient housing design (EEHD) in South Africa. Department of Housing: Pretoria.

Holm, D. and Viljoen, R. 1996 Manual for energy conscious design. Department of Mineral and Energy Affairs: Pretoria.

Holm, D. 1997. Climate Conscious Design. Architecture S A (July/August 1997).

Palmer Development Consulting. 2003. Marketing zero energy houses in South Africa. Final Project Report to the Dutch Ministry of Foreign Affairs.

Sekhonyana, P. 2004. Department of Housing presentation at the Housing for a Healthier Future Information Session. Department of Housing presentation on 6 February 2004, African Window Conference Centre: Pretoria.

Terblanche, P; Nel, C.M and Opperman, L. 1992. Health and safety aspects of domestic fuels. Department of Minerals and Energy: Pretoria. Final Report NE14/6/30.

Trade and Industry Chamber. 2004. Fund for Research into Industrial Development Growth and Equity (FRIDGE). Study to examine the potential socio-economic impact of measures to reduce air pollution from combustion. Final Report.

Swedish Standards Institute. 2004. Thermal performance and energy use in the built environment. European Union.

Received 9 February 2005; revised 24 October 2005 